\section{Building the evidence base for safe and active bicycling: an historical commentary on Rivara et al: epidemiology of bicycle injuries and risk factors for serious injury}

\author{
Beth E Ebel, Brent E Hagel
}

It has been 17 years since Rivara et al ${ }^{1}$ published their manuscript on the "Epidemiology of bicycle injuries and risk factors for serious injury". The authors reported on crash circumstances and preventive measures. Using data from their seminal case-control study on bicycle helmet effectiveness, the study reported on crash circumstances, helmet use and injury outcomes to identify prevention opportunities. This study was part of a broader intellectual effort to engage rigorous epidemiological science in the gritty real-world work of injury prevention: identifying modifiable crash risk factors, ${ }^{1}$ measuring helmet effectiveness $^{2}$ and putting this knowledge to work in a large controlled community campaign. ${ }^{3}$

The work of Rivara et al is important for its contributions to methodological rigour and public health. Case-control studies are efficient and valid design choices for studying injury aetiology. Key to this design is the proper selection of a control group that represents the exposure experience of the source population that produced the cases of the outcome. ${ }^{4}$ In this situation, the cases were those with serious injuries defined by ISS, hospitalisation or fatality. This efficient use of numerator data separated into severe and non-severe injuries representing cases and

'Department of Pediatrics, University of Washington, Seattle, Washington, USA; '2Department of Paediatrics, University of Calgary, Calgary, Alberta, Canada

Correspondence to Dr Beth E Ebel, Department of Pediatrics, University of Washington, 325 Ninth Ave, Box 359960, Seattle, WA 98104-2499, USA; bebel@uw.edu controls remains an elegant approach for attacking the injuries that will have significant healthcare system, economic and personal consequences.

From a public health perspective, bicycling injuries remain the most common cause of sport and recreation-related injuries in children and adolescents. ${ }^{5}$ As municipalities look to increase the appeal and efficiency of bicycling to address issues such as traffic congestion, physical activity and environmental sustainability, reducing bicycle injuries becomes increasingly important. Rivara et al noted determinants of severe bicycle-related injuries that are relevant to today's city planners. Their results emphasised that serious injury is preventable, and helmet use was associated with a reduction in fatal injury. The findings also highlighted the need to address the sometimes competing interests of cars and cyclists-areas in which today's planners are designing creative infrastructure and regulation for healthier cities. There are new opportunities to promote safe and active transport, so that bicycling and other active transportation options continue to grow, in part, because they become safer for learners and skilled riders alike.

The most powerful contribution of this article is its commitment to evidence-based injury prevention strategies in the context of public health. During the past 30 years, leaders in injury science have moved the public debate away from emotional appeals and towards a scientific approach that takes a hard-nosed look at the effectiveness of strategies. There is relevance for this debate today, as a number of people have pushed back against the idea of bicycle helmet promotion and other safety strategies in the absence of rigorous study. In Dr Rivara's words, 'As injury control professionals, we need to demand that those who oppose studies show us convincing data that refutes previous work'.

Finally, the ideas for the bicycle helmet studies came from the experience of clinicians who cared for children and adults with bicycle-related traumatic brain injuries and felt that there must be ways to prevent these injuries from occurring. Like most real-world studies, it was collaborative, involved different institutions and scientists with different backgrounds and began from a small grant from a local foundation. The study by Rivara et al is a landmark example of engaged and rigorous injury science.

Contributors This article was jointly written and edited by BEE and BEH.

Competing interests None.

Provenance and peer review Not commissioned; internally peer reviewed.

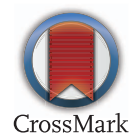

To cite Ebel BE, Hagel BE. Inj Prev 2015;21:52.

Inj Prev 2015;21:52.

doi:10.1136/injuryprev-2014-041516

\section{REFERENCES}

1 Rivara FP, Thompson DC, Thompson RS. Epidemiology of bicycle injuries and risk factors for serious injury. Inj Prev 1997;3:110-14.

2 Thompson RS, Rivara FP, Thompson DC. A casecontrol study of the effectiveness of bicycle safety helmets. N Engl J Med 1989;320:1361-7.

3 DiGuiseppi CG, Rivara FP, Koepsell TD, et al. Bicycle helmet use by children. Evaluation of a community-wide helmet campaign. JAMA 1989;262:2256-61.

4 Rothman K, Greenland S, Lash T. Modern epidemiology. 3rd edn. Philadelphia, PA: Lippincott Williams \& Wilkins, 2008.

5 HealthCanada. For the safety of Canadian children and youth. From injury data to preventive measures. Ottawa, Canada: Minister of Public Works and Government Services Canada, 1997.

6 Rivara FP, Grossman D. Injury control. In: Behrman RE, Kliegman RM, Jenson HB, eds. Nelson textboook of pediatrics. 17th edn. Philadelphia: Saunders, 2004. 